\title{
VOLENTI NON FIT INIURIA: CONSENTIMIENTO, INTERCAMBIO PRODUCTIVO Y PRECIO JUSTO EN ANARQUÍA, ESTADO Y UTOPÍA DE ROBERT NOZICK
}

\author{
VOLENTI NON FIT INIURIA: CONSENT, PRODUCTIVE EXCHANGE \\ AND FAIR PRICE IN ROBERT NOZICK'S ANARCHY, STATE, AND \\ UTOPIA
}

\section{Felipe Schwember Augier*}

RESUMEN: El presente trabajo se detiene en dos aristas de la teoría de los contratos que Nozick presenta en "Anarquía, Estado y utopía": el de la voluntariedad y el de la productividad de los intercambios. Se sostendrá que, sin perjuicio de los aciertos generales de su teoría de los intercambios, la estrecha noción de voluntariedad que adopta Nozick le conduce a conclusiones contraintuitivas, que cierran los posibles vasos comunicantes entre su teoría del título válido y la justicia distributiva. Por otra parte, se defenderá la pertinencia del requisito de productividad de los intercambios exigido por Nozick, especialmente como un modo de paliar las dificultades a que conduce su estrecha noción de voluntariedad en materia contractual. Se sostendrá, por último, la concordancia entre esta exigencia de productividad con los principios más generales de la obra y, particularmente, con el "principio kantiano subyacente" que le sirve de inspiración general.

Palabras clave: Nozick, justicia conmutativa, intercambio productivo, precio justo.

ABSTRACT: This paper focuses on two aspects of Nozick's theory of contracts presented in Anarchy, State, and Utopia: the voluntariness and productivity of exchange. It will be argued that, without detriment to the general success of his theory of exchange, the narrow notion of voluntary act which Nozick assumes leads him to counterintuitive conclusions, excluding possible links between commutative and distributive justice. Moreover, the relevance of the requirement of productivity of exchange demanded by Nozick will be defended as a way to alleviate the difficulties that derive from his narrow notion of voluntary act in contractual matters. It will be held, finally, that there is a correlation between his demands for productivity and the general principles of this particular work and, especially, that there is coherence between these demands and the "underlying Kantian principle" that works as general inspiration of this book.

Key words: Nozick, commutative justice, productive exchange, fair price.

\footnotetext{
* Dr. en Filosofía por la Universidad de Navarra. Profesor de la Escuela de Gobierno, Universidad Adolfo Ibáñez. Dirección postal: Padre Hurtado 750, Viña del Mar. Correo electrónico: felipe.schwember@uai.cl. El presente trabajo forma parte del proyecto Fondecyt no 1160982, titulado "Crítica y recepción de las utopías y del utopismo en el liberalismo libertario y en el liberalismo socialdemócrata del siglo XX: Popper, Hayek, Nozick y Rawls". Agradezco los comentarios y sugerencias de José de la Cruz Garrido.
} 


\section{INTRODUCCIÓN}

En Anarquía, Estado y utopía ${ }^{1}$, Robert Nozick presenta una teoría de la justicia de los intercambios o, como también podría denominársela, una teoría de la justicia contractual. El grueso de esta teoría es desarrollada en la segunda parte de la obra, con ocasión de la formulación y explicación de la teoría del título válido. Allí Nozick recurre a dicha teoría para demostrar la tesis general de su investigación, esto es, que el Estado mínimo es el único moralmente admisible. En este sentido, la teoría del título válido tiene por cometido demostrar que cualquier distribución de bienes que no sea fruto de un acuerdo voluntario es moralmente indefendible. Anticipándose a la objeción que podría levantarse contra esta tesis -y que podría conducir a la justificación de un Estado mayor al Estado mínimo-, Nozick añade que las elecciones hechas bajo el apremio de la necesidad deben contar también como voluntarias. De este modo, y gracias a esta concepción de la voluntariedad, la teoría de los intercambios de Nozick -que podría resumirse bajo el viejo aforismo volenti non fit iniuria, "al que consiente no se le hace daño"- permite afirmar la inmoralidad de cualquier medida redistributiva y, con ello, la necesidad del programa libertario.

Un aspecto importante de la teoría, sin embargo, es presentado en la primera parte de ASU, al hilo del argumento a favor del Estado. En el decurso de dicho argumento, y para probar la licitud de la compensación dada al independiente por la prohibición que se le impone de hacerse justicia por su propia mano, Nozick introduce la exigencia de productividad recíproca de los intercambios. Según esta exigencia, un intercambio solo es justo si aprovecha a ambos contratantes. Con ella Nozick está -a diferencia de otros autores libertarios o anarcocapitalistas- en condiciones de excluir de modo inequívoco el chantaje y la protección gansteril de entre los intercambios válidos. Sin embargo, la introducción de esta exigencia de productividad, dicen sus críticos, entraña graves dificultades en la medida en que, o conduce al problema del precio justo ${ }^{2}$, o desemboca en consecuencias que resultan inconsistentes con el programa libertario ${ }^{3}$.

Como se desprende de lo anterior, la teoría de los intercambios de Nozick suscita, de cara a la exégesis de ASU, fundamentalmente tres problemas: 1) el de la idoneidad del concepto de voluntariedad que adopta Nozick y el de sus consecuencias para una teoría global de la justicia; 2) el del sentido de la exigencia de productividad de los intercambios y el de su relación con el problema del precio justo y, 3) el de la consistencia entre la exigencia de productividad y el programa libertario defendido por Nozick ${ }^{4}$.

\footnotetext{
1 Abreviada en lo sucesivo por sus iniciales en inglés, ASU. Las obras de autores clásicos como Aristóteles o Kant se las cita del modo canónico. Las citas de ASU están tomadas de la edición castellana, que se adopta con algunas correcciones.

2 RotbHard (1995) pp. 313 y ss.

3 MACK (1982).

4 Evidentemente, estos tres no son los únicos problemas suscitados por la teoría de los contratos de Nozick. Los tres problemas aquí abordados, por tanto, no agotan -ni mucho menos- la investigación acerca de la teoría de los intercambios presentada en ASU. Por de pronto, y como el lector podrá apreciar, el presente trabajo trata tan solo de modo somero y circunstancial algunos de los problemas vinculados a o suscitados por una teoría general de los contratos (por ejemplo, la incidencia de la teoría del valor en una teoría conmutativa de la justicia); otras cuestiones son aun aquí completamente omitidas (como por ejemplo, la pertinencia de las críticas de
} 
El presente trabajo examina la teoría de los contratos de Nozick y, en consecuencia, se detiene en cada uno de los tres problemas recién indicados. Por eso, y después de exponer brevemente la teoría del título válido, se examinará primero tanto la plausibilidad de la noción de voluntariedad de Nozick como las consecuencias que, con vistas al programa libertario, quiere sacar de ella. Se sostendrá que, aunque el principio general al que puede reducirse su teoría de los intercambios, volenti non fit iniuria, es correcto, la noción concreta de voluntariedad que adopta Nozick en ASU no lo es. En este sentido, se sostendrá que una concepción más diferenciada, que admite grados de voluntariedad -como por ejemplo la manejada por Aristóteles y sus epígonos- es preferible a la adoptada por Nozick, en la medida en que permite evitar ciertas conclusiones contraintuitivas en la aplicación de su propia teoría del título válido y, al mismo tiempo, tender puentes hacia la justicia distributiva.

En seguida se abordará el requisito de productividad recíproca exigido por Nozick para la validez de los intercambios. Aquí no nos referiremos al argumento en favor del Estado mínimo ni, más concretamente, a si el mentado requisito es exitoso como parte del argumento en favor de la proscripción de la justicia privada ${ }^{5}$. Nos limitaremos a ofrecer una interpretación de tal requisito y a abordar las consecuencias que tiene en general para la teoría del título válido. En este sentido, más que ofrecer una refutación puntual de cada una de las objeciones que han dirigido Rothbard y Mack a Nozick, nos limitaremos a ofrecer una explicación alternativa de la exigencia de productividad de los intercambios, interpretación que evita dichas objeciones y subraya, al mismo tiempo, la continuidad entre dicho requisito y la teoría del título válido. Sí nos detendremos en la cuestión de si acaso la exigencia de productividad recíproca reclama o supone una cierta concepción del precio justo y si, de hacerlo, entraña ello problemas para la teoría de los intercambios de Nozick. A este respecto se concluirá, contra Rothbard, dos cosas. Primero, que la teoría del título válido gana y no pierde con la introducción del requisito de productividad en la medida en que con ella, y a diferencia de sus detractores libertarios y anarcocapitalistas, Nozick está en condiciones de incorporar el principio general de la buena fe contractual; segundo, que la noción de intercambio productivo no reclama para su inteligibilidad ninguna noción de precio justo que sea incompatible con la teoría de la justicia de Nozick.

Finalmente, con la interpretación aquí defendida, se espera poner de manifiesto no solo la consistencia entre el requisito de productividad de los intercambios y la teoría del título válido, sino, más aún, poner de manifiesto la continuidad que existe entre tal requisito y el principio más general del libertarismo, tal como lo concibe Nozick, el "principio kantiano subyacente". En este sentido, se sostendrá que el requisito de productividad de los intercambios puede ser entendido como una prolongación de dicho principio a las condiciones de la justicia contractual. Con todo ello se espera dejar de manifiesto no solo

Nozick a Rawls a partir de su propia teoría conmutativa de la justicia). Como se ha señalado arriba, aquí se ha procurado abordar únicamente aquellos problemas que guardan relación directa con la exégesis de la teoría de los intercambios de Nozick. Espero abordar los restantes problemas en otros artículos, dentro del mismo proyecto de investigación en que se inscribe el presente trabajo.

5 Para una exposición general del argumento de Nozick en favor del Estado, cf., por ejemplo, WolfF (1991) pp. 36 y ss., Gaus (2011) o Hunt (2015) pp. 70 y ss. 
la pertinencia y utilidad del concepto de intercambio productivo, sino también la unidad y coherencia de la teoría de los intercambios de Nozick.

\section{LA TEORÍA DEL TÍTULO VÁLIDO (ENTITLEMENT THEORY)}

En la segunda parte de ASU, Nozick formula la teoría del título válido en los siguientes términos:

"Si el mundo fuera completamente justo, las siguientes definiciones inductivas cubrirían exhaustivamente la materia de justicia sobre pertenencias.

1) Una persona que adquiere una pertenencia, de conformidad con el principio de justicia en la adquisición, tiene derecho a esa pertenencia.

2) Una persona que adquiere una pertenencia de conformidad con el principio de justicia en la transferencia, de algún otro con derecho a la pertenencia, tiene derecho a la pertenencia.

3) Nadie tiene derecho a una pertenencia excepto por aplicaciones (repetidas) de 1 y 2.

El principio completo de justicia distributiva diría simplemente que una distribución es justa si cada uno tiene derecho a las pertenencias que posee según la distribución"6.

En las páginas que siguen explica, en términos generales, el modo en que deben entenderse estas proposiciones. Para tales efectos distingue entre distintos tipos de principios distributivos de la propiedad (teorías de resultado final, históricas, etc.) para, luego, aclarar que la suya, la teoría del título válido, es una teoría histórica y no pautada de la propiedad. Esto significa, en primer lugar, que de acuerdo a la misma, no se puede saber si una distribución cualquiera es justa sin atender a cómo han llegado las cosas al poder de aquellos que actualmente las detentan; dicho de otro modo, no se puede saber si una distribución es justa sin atender a la historia del título respectivo. La contraposición aquí es con las "teorías de resultado final", esto es, con aquellas teorías según las cuales una distribución es justa cuando contribuye a la consecución de algún fin, de algún estado de cosas que se considera -por los motivos que fuere- como justo. Un ejemplo típico -y bastante discutible- sería una teoría utilitarista de la propiedad.

En segundo lugar, y por lo que toca a su carácter de "no pautada", la teoría entiende que la justicia o rectitud de una determinada distribución depende única y exclusivamente de que esta sea el resultado de intercambios voluntarios. El contrapunto lo ofrecen aquí las teorías pautadas de la propiedad, esto es, aquellas que sostienen que una distribución solo puede considerarse justa en la medida en que varíe "de conformidad con alguna dimensión natural, con la suma de pesos de las dimensiones naturales de conformidad con un orden

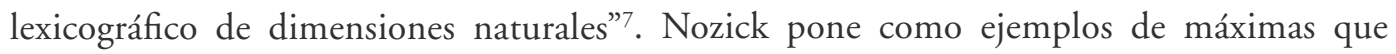
corresponden o corresponderían a teorías pautadas aquellas que sostienen que a cada cual debe darse según su mérito moral, o según sus necesidades, o según su producto marginal, etc. La teoría del título válido no incluye ninguna pauta y, más aún, rechaza la pertinencia de incluir alguna. Por ese motivo, al momento de allanarse a la costumbre de expresar su

\footnotetext{
Nozick (1988) p. 154.

Nozick (1988) p. 159.
} 
propia teoría según la socorrida fórmula "de cada quien según su a cada quien según ___ ”, Nozick lo hace en los siguientes términos: "de cada quien como escoja, a cada quien como es escogido"s.

Creo que es posible simplificar aún más la máxima que subyace a la teoría del título válido de Nozick apelando al conocido aforismo jurídico volenti non fit iniuria, "al que consiente no se le hace daño". Tal teoría -y a fin de cuentas toda la filosofía política de Nozick- expresa cabalmente ese principio, en virtud del cual cualquier distribución de bienes que resulte de los intercambios que libre y voluntariamente celebren las personas es, sin más, justa. Y a la inversa, que cualquier distribución que sea resultado del error, la fuerza o el fraude ("dolo" en términos jurídicos) es, sin más, injusta. De ahí que los intercambios que no hayan sido realizados de conformidad con el principio volenti non fit iniuria queden expuestos al principio de rectificación, que Nozick no incluye en la formulación recién citada pero que añade inmediatamente después. En virtud del mismo, las apropiaciones viciosas deben ser deshechas por la vía de retrotraer a las partes al estado en que se encontraban antes de que estas tuvieran lugar.

\section{VOLUNTARIEDAD, INTERCAMBIO PRODUCTIVO Y PRECIO JUSTO}

La teoría del título válido es prima facie muy simple. No obstante, en varios pasajes de $A S U$ recibe elaboraciones ulteriores que introducen en ella distintos grados de complejidad. Hasta cierto punto esto es inevitable, pues los tres principios mediante los cuales Nozick la formula son meramente formales. Llegado un momento es necesario explicar en qué consiste exactamente una apropiación originaria justa, una adquisición derivativa justa o, en fin, en qué consiste ofrecer una indemnización suficiente en favor de aquel que ha padecido una injusticia. Así, por ejemplo, y tomando en cuenta todas las explicaciones que Nozick ofrece a propósito de la adquisición original y la estipulación de Locke, el principio de justicia en la adquisición podría rezar del siguiente modo:

"El que trabaja una res nullius deviene dueño de la misma si y solo si con ello no empeora la posición de todos los demás, esto es, no les impide ni les hace más gravoso el uso de otras cosas del mismo género de la que él se apropia”.

El principio de justicia en las trasferencias, por su parte, podría formularse en los siguientes términos:

"El que obtiene un bien en virtud de la transmisión voluntaria que del mismo le hace su dueño, adquiere ese bien si y solo si con ello no empeora la posición de todos los demás, esto es, no les impide ni les hace más gravoso el uso de otras cosas del mismo género de la que él se apropia”.

Evidentemente, la condición añadida en ambos casos mediante la fórmula "si y solo si" refleja las exigencias impuestas por la estipulación de Locke ("no empeorar la posición de los demás mediante las propias adquisiciones”). Dicha estipulación abre interesantes vías de investigación respecto de las condiciones de validez y del alcance tanto de las adquisiciones originarias como respecto de las adquisiciones derivativas. Por ejemplo, en el caso de las

\footnotetext{
Nozick (1988) p. 163.
} 
primeras, acerca del modo en que deben tratarse las externalidades negativas de ciertas actividades económicas (por ejemplo la contaminación de bienes comunes) o, por lo que toca a las adquisiciones derivativas, a la licitud de los monopolios y, eventualmente $-\mathrm{y}$ en virtud de una aplicación analógica de la estipulación- de la formación de carteles y otras prácticas anticompetitivas. Otro tanto sucede con el modo originario de adquirir que admite Nozick, el trabajo. Como él mismo observa, algunas de las dificultades de la teoría de la propiedad tienen que ver con el de los límites de la adquisición, con lo que se deba entender por "mezclar" mi trabajo con una cosa que no tiene dueño, con explicar por qué no podría ocurrir que yo pierda mi trabajo más que ganar la cosa al "mezclar" ambas, etc.

Sin embargo, aquí nos detendremos en el requisito de voluntariedad exigido a los intercambios. Como ocurría con la formulación general de la teoría del título válido, la exigencia de voluntariedad como condición necesaria y suficiente de la justicia de los intercambios esconde más problemas de lo que prima facie parece encerrar. Dichos problemas son, al menos, los siguientes: a) ¿qué debe entenderse por “voluntario"?; b) ¿es relevante para efectos de la teoría el que la voluntariedad sea susceptible de grados?; c) ¡es realmente no solo necesaria sino también suficiente la exigencia de voluntariedad para considerar un intercambio como "justo"?

\section{a) VolUnTARIEDAD, JUSTICIA CONMUTATIVA Y PRECIO JUSTO}

Nozick no ofrece una definición de "voluntariedad" o de "acto voluntario". En cambio, ofrece una suerte de delimitación de lo voluntario en los siguientes términos:

"Algunos lectores objetarán que yo hable frecuentemente de intercambios voluntarios sobre la base de que algunas acciones (por ejemplo, trabajadores que aceptan una posición asalariada) no son realmente voluntarias, porque una parte se enfrenta a opciones severamente limitadas, en que todas las demás son mucho peores que la que escoge. Que las acciones de una persona sean voluntarias depende de lo que limita sus alternativas. Si los hechos de la naturaleza lo hacen, las acciones son voluntarias. (Puedo voluntariamente caminar hasta algún lugar al que yo preferiría volar sin ninguna ayuda.) Las acciones de otras personas ponen límites a las oportunidades disponibles de uno. Si esto hace la acción no voluntaria, depende de si los otros tienen el derecho de actuar como lo hicieron"'.

En este pasaje y en los que siguen, Nozick procura salir al paso de la eventual objeción de que la necesidad vicia la justicia de los intercambios. Puesto que, de acuerdo a los términos de su propia teoría, la falta de voluntad conlleva la nulidad del acuerdo, podría concluirse que los intercambios celebrados bajo el apremio de la necesidad no son justos. Sin embargo, Nozick desecha expresamente esta posibilidad. Un poco más adelante lo hace de un modo incluso más enfático cuando dice:

" $Z$ se enfrenta a la alternativa de trabajar o morirse de hambre; las selecciones y acciones de todos los demás no se suman para dar a $Z$ alguna otra opción (él puede tener

\footnotetext{
9 Nozick (1988) p. 255.
} 
varias opciones acerca de qué trabajo tomar) ¿escoge $Z$ trabajar voluntariamente? (¿Lo hace en una isla desierta alguien que debe trabajar para sobrevivir?)" 10 .

Ciertas precisiones con respecto a los efectos de la necesidad en la teoría de Nozick podrían ser oportunos para deslindar el problema que esta suscita respecto a la justicia de los intercambios.

Es claro que Nozick no cree que la necesidad pueda ser sin más desestimada por la teoría de la justicia. La estipulación de Locke, como se adelantaba, puede obligar a paliar la necesidad de un tercero en la medida en que esta es consecuencia de la propia adquisición. Más aún, en virtud de dicha estipulación, una persona puede estar obligada simplemente a mantener la posición relativa de alguien aun cuando, por otra parte, dicha posición esté muy por sobre la necesidad. Pero es evidente que en los pasajes precedentes Nozick no se refiere a la necesidad causada de esta forma. Para que la estipulación opere, la necesidad debe ser causada a un tercero por una adquisición originaria o derivativa y, por lo mismo, imputable a el o los adquirentes. La necesidad que tenga cualquier otra causa no permite invocar la estipulación de Locke y, además, no modifica, cree Nozick, la voluntariedad de los actos.

Teniendo esto en cuenta ¿cuál es la delimitación de la voluntariedad que Nozick hace en los dos pasajes recién citados? Y admitiendo que en un punto dicha delimitación resulta contraintuitiva ¿en dónde radica su falla?

El primero de los pasajes citados recuerda aquel de la Ética a Nicómaco en que Aristóteles dice que no hay elección de lo imposible y que "si alguien dijera elegirlo, parecería un necio"11; que la deliberación es solo "de lo que está a nuestro alcance y es realizable"12. De modo semejante a Aristóteles, Nozick quiere subrayar que el objeto de la elección es "algo que está en nuestro poder y es tema de deliberación y deseable"13. En este sentido, a la pregunta de cómo delimita Nozick el ámbito de lo voluntario, podría responderse diciendo que son voluntarias aquellas cosas que está en nuestro poder hacer o no. Sin embargo, en el pasaje citado Nozick no se refiere únicamente a esta cuestión. Como lo que se discute es la justicia de los intercambios, añade además, con vistas a la defensa del programa libertario, que todos aquellos factores que no sean directamente imputables a otros y que favorezcan o impidan nuestro obrar colaborando o estorbando así en la consecución de nuestros propósitos no modifican la voluntariedad de nuestros actos, al menos por lo que a la celebración de los intercambios respecta. La tesis de Nozick, en resumen, es que las circunstancias bajo las cuales se contrata no modifican en absoluto la voluntariedad de los actos cuando estas no son imputables a otra persona (que obra contra derecho). Es por la locución adverbial "en absoluto" por lo que la posición de Nozick resulta contraintuitiva. Pero antes de referirnos a las dificultades a que su concepción se enfrenta, permítasenos suponer otra lectura que, aunque descaminada como vía de impugnación de la postura de

\footnotetext{
10 Nozick (1988) p. 255.

11 Aristóteles, EN., III, 2 1111b20-22.

12 Aristóteles, EN., III, 2 1112a30-31.

13 Aristóteles, EN., III, 2 1113a8-9.
} 
Nozick, resulta interesante por las consideraciones que introduce y porque puede interpretar las aprensiones de más de algún lector descontento con Nozick.

En los pasajes citados - podría decir esta lectura alternativa- y particularmente en el primero de ellos, Nozick trata sumaria y conjuntamente aspectos que es mejor distinguir, pues los hechos de la naturaleza y los derechos de otros ciertamente limitan lo que podemos hacer, pero no del mismo modo: mientras los hechos de la naturaleza imponen restricciones meramente físicas, los derechos de terceros imponen restricciones morales a lo que podemos hacer. Lo primero no significa únicamente que las restricciones naturales sean insuperables. Además de eso significa que carecen de relevancia moral. Así, no solo no tiene sentido deliberar acerca de si resultaría conveniente o no tener alas (o ser invisible o atravesar las paredes, etc.), sino que además carece de relevancia moral el que las tengamos o no. La razón de esta irrelevancia estriba en que la naturaleza se nos presenta como un conjunto de hechos brutos en cuya configuración no nos ha cabido ninguna responsabilidad. Y como la imputabilidad es condición de cualquier juicio moral, no tiene sentido dirigirle a alguien reproches por dicha configuración ${ }^{14}$. Los derechos de terceros, en cambio, imponen una limitación moral y no física a nuestras acciones. Las restricciones libertarias que Nozick expone y defiende en la primera parte de ASU, por ejemplo, ordenan pero no impiden que una persona transgreda los derechos naturales libertarios. Según dichas restricciones, yo no debo matar como no sea en defensa propia. Si pese a eso doy muerte a un inocente (a sabiendas de que lo es, queriendo hacerlo, sin mediar una causal de justificación, etc.) entonces he obrado voluntaria e ilícitamente. En consecuencia, respecto de los hechos que inciden en el espacio moral -y a diferencia de hechos de la naturaleza como una avalancha o un atardecer- es pertinente preguntarse no solo si son voluntarios sino, además, si son justos.

En virtud de estas distinciones ¿no podría argüirse que el tratamiento de Nozick de lo voluntario encubre la diferencia que existe entre ambas clases de limitaciones? ¿No nivela las limitaciones morales sobrevinientes con las limitaciones naturales? Más específicamente, tal tratamiento podría encubrir la diferencia, pertinente para los actos que inciden en el espacio moral, entre actos voluntarios y actos justos. Y así como un homicidio es voluntario e injusto - podría concluir esta lectura alternativa- el acuerdo en virtud del cual un trabajador conviene en un salario de subsistencia puede ser considerado voluntario pero injusto.

Esta posible lectura niega el principio fundamental del que parte Nozick, el principio volenti non fit iniuria. En ese sentido -y concediendo que se pudiera abandonar dicho principio, lo que es una grandísima concesión ${ }^{15}$ - esta lectura alternativa ofrecería en el mejor de

\footnotetext{
14 En términos más generales, los juicios morales acerca de la constitución del mundo solo podrían tener sentido si pudiera afirmarse con verosimilitud que la constitución del mundo debería haber sido, con vistas a la consecución de la justicia, una en lugar de otra. Si ese fuera el caso, entonces -y por volver al ejemplo de Nozick- podría decirse con propiedad que la naturaleza debería haberme dado alas y que ha sido injusta al no hacerlo. Si se entiende que la constitución del mundo no obedece a un plan moral o que, obedeciéndolo, no tiene por qué ser aquel que nosotros consideramos como el más razonable, los juicios acerca de lo injusta que es la naturaleza no pueden ser tomados sino como una metáfora de nuestra propia finitud o como una lamentación de que la naturaleza no se adecue a nuestros propios fines.

15 De hecho, podría replicar Nozick, el homicidio precisamente es injusto porque es involuntario: el que muere no quiere ser muerto. En términos generales, la víctima lo es porque no quiere serlo. Por eso Nozick afirma que el consentimiento abre la frontera descrita por los derechos naturales (NozicK (1988) p. 67).
} 
los casos una crítica extrínseca a su teoría de la justicia. No obstante, vale la pena llamar la atención sobre esta posible lectura, no solo porque algún lector podría creer que ella detecta la falla en la posición de Nozick, sino porque además pone en primer plano el elusivo problema del precio justo: el acuerdo al que llega el trabajador es voluntario e injusto cuando no se le retribuye su trabajo en su precio justo.

Volveremos sobre el problema del precio justo. Por el momento baste para desechar esta lectura el que ella niegue la identidad, asumida por Nozick, entre voluntariedad y justicia. De acuerdo a su teoría, la distinción entre voluntariedad y justicia es redundante: si un intercambio es voluntario entonces es necesariamente también justo. Volenti non fit iniuria. Después de todo, podría responder Nozick, ¿qué criterio diferente e independiente de la voluntad de cada contratante podría ofrecerse para juzgar la rectitud de un acuerdo? Con respecto a la rectitud de los intercambios, por tanto, la pregunta no es si existe un precio justo "objetivo" que pueda determinarse haciendo abstracción de las preferencias de los contratantes sino, tan solo, si estos han obrado o no voluntariamente. Por consiguiente, con respecto al caso del trabajador asalariado la pregunta no es si el salario es "justo" de acuerdo con algún criterio abstracto, sino si este último ha contratado voluntariamente hic et nunc. Si así ha sido, entonces el salario es justo. El único modo de impugnar la validez de un contrato sería, entonces, probando que "en realidad" el trabajador no ha consentido voluntariamente en él.

\section{b) ACTOS MiXTOS, JUSTICIA CONMUTATIVA Y PRECIO JUSTO}

Supongamos que no existe un criterio objetivo para determinar el precio justo de algo. Eso nos obliga a concentrarnos en el problema de la voluntariedad. Supongamos además que la voluntariedad es la medida de la justicia de los intercambios (suposición esta que no debiera resultar demasiado difícil: el principio volenti non fit iniuria es un principio muy fuerte y el derecho privado no puede abandonarlo sin dejar de ser lo que es). Pues bien, hechas todas esas suposiciones ¿qué puede decirse del caso del trabajador del ejemplo de Nozick? ¿Obra voluntaria o involuntariamente? ¿Lleva razón Nozick?

La respuesta más probable a esa pregunta es "sí y no". En cierto sentido es indudable que el trabajador asiente y que podría no hacerlo si así quisiera. En otro es igualmente cierto que los altísimos costos de su negativa llevan a considerar su obrar como forzado, o casi forzado. Dicho en términos hegelianos, tanto la postura de Nozick como la postura que sostuviera lo contrario afirmarían unilateralmente una verdad, una verdad meramente abstracta: mientras una prescinde de las circunstancias, la otra prescinde de la libertad. ¿o hay acaso un tertium quid que permita resolver de modo más satisfactorio el problema del ejemplo de Nozick? Pues la posición de Nozick acerca de este problema puede aparecer inverosímil a causa de la concepción binaria "voluntario/involuntario" que parece servirle de orientación.

Lo más probable es que en casos como el del trabajador asalariado que describe Nozick, la voluntad esté dividida y, por consiguiente, el trabajador quiera y no quiera consentir en el acuerdo a un mismo tiempo; lo más probable es que ninguna de las alternativas le resulte particularmente halagüeña y se decante con resignación por la que le parezca menos mala. Aristóteles llama a los actos elegidos bajo esas circunstancias como actos mixtos de 
voluntario con involuntario ${ }^{16}$. Puede discutirse si los actos mixtos son más propiamente voluntarios o involuntarios (y el mismo Aristóteles parece oscilar a este respecto). Lo que aquí interesa es simplemente llamar la atención sobre esta categoría que ofrece no solo un tertium quid para juzgar de modo más satisfactorio la situación en que se encuentra el trabajador del ejemplo, sino también la oportunidad de introducir matices en el tratamiento que Nozick ofrece de la justicia contractual y, con ello, en el conjunto de su teoría del título válido.

Asumiendo entonces que se puede atribuir a Nozick sin problemas la definición estándar de "acto voluntario" como aquel "cuyo principio está en uno mismo y que conoce las circunstancias concretas de la acción"17; y asumiendo, además, que la dicotomía voluntario-involuntario no da buena cuenta del modo en que de hecho obran normalmente los agentes, cabe entonces preguntarse ¿cómo afecta o, mejor dicho, cómo debería afectar la inclusión de lo mixto de voluntario con involuntario la teoría del título válido de Nozick?

Para ensayar una respuesta a esta pregunta puede resultar ilustrativo considerar el tratamiento que algunos de los epígonos de Aristóteles -y particularmente los escolásticos salamantinos que, como Nozick, profesan una teoría histórica de la propiedad- dispensan a estos mismos problemas (i.e., el de la relación entre la voluntariedad y la justicia conmutativa).

Tales autores suelen abordar la dificultad de la justicia de los acuerdos celebrados con voluntad mixta a propósito de la cuestión que Tomás de Aquino plantea en II-IIae q. 59, a.3, acerca de si alguien puede sufrir lo injusto voluntariamente. Aunque en principio la respuesta es "no", tales autores introducen varios matices. Así, por ejemplo, Domingo de Soto afirma que si alguien por necesidad vende o conviene en un préstamo usurero, aunque dé su consentimiento, puesto que por otra parte no quiere darlo, sufre injuria ${ }^{18}$. Vitoria, por su parte, formula lo que puede considerarse como la regla general a propósito de casos como el que cita Domingo de Soto, en que el contrato es en parte voluntario y en parte involuntario: "en las conmutaciones humanas no es suficiente para la justicia conmutativa el que por ambas partes sea algo absolutamente voluntario, sino que es necesario que no tenga mezclado algo de involuntario" ${ }^{19}$. De aquí, podríamos añadir, se sigue que mientras mayor la involuntariedad (expresada en reticencia, resignación, etc.), mayor la injusticia; mientras más apremiante sea la necesidad de alguien, menos voluntario será su consentimiento a una oferta oportunista o abusiva; y mientras menos voluntario sea el acuerdo por su parte, más injusto este es.

La introducción del tertium quid representado por la categoría de los actos mixtos ofrece una solución al problema suscitado por la relación entre voluntariedad, necesidad y justicia contractual mejor que cualquiera otra que se quiera ensayar y que prescinda de

\footnotetext{
16 Aristóteles, EN, III, 1.

17 Aristóteles EN., III, 2 1111a23-24; cf. también Tomás de Aquino, S. T., II-IIae, q. 6, a. 1; o Pufendorf, De jure naturae et gentium I, V, S1: "Voluntarias actiones vocamus illas, quae à voluntate hominis tanquam à causa libera ita dependent, ut citra ipsius determinationem, ab actibus ejusdem elicitis praevia cognitione intellectus profectam, non fierent; quaeque adeo, ut fiant vel no fiant, in facultate hominis est positum".

18 De Soto, De la justicia y del derecho, III, q.3, a.3.

19 Vitoria (2006) p. 92.
} 
tal categoría ${ }^{20}$. Dicho en términos rawlsianos, la consideración de la categoría de los actos mixtos nos permite formular juicios respecto de la justicia contractual bajo condiciones de necesidad que casan con nuestros "juicios morales bien ponderados". La prescindencia de dicha categoría, en cambio, nos relega a una falsa disyuntiva. Por consiguiente, y en aras de una interpretación realista y menos dogmática del principio volenti non fit iniuria, resulta conveniente incorporar la categoría de actos mixtos en la teoría del título válido. Si Nozick la hubiera adoptado, podría haber evitado ciertas consecuencias contraintuitivas como, por ejemplo, decir que el contrata bajo necesidad contrata sin embargo voluntariamente; o que -en razón de esa misma voluntariedad- no existe ninguna obligación jurídica de prestar ayuda a aquellos que, no pudiendo invocar la estipulación de Locke, padecen necesidad sin culpa de su parte ${ }^{21}$.

Pero eso no es todo. La introducción de la categoría del acto mixto podría haber redituado a Nozick aún de otra manera: en la medida en que el derecho privado no puede hacerse cargo de modo sistemático de la eventual invalidez de todos los contratos celebrados con voluntad mixta ${ }^{22}$, la admisión de ese deber de auxilio le habría abierto vías de comunicación con la justicia distributiva (y con ello al derecho público). Desde la justicia distributiva, entonces, podría haber ideado medidas que remediaran indirectamente la situación de los contratantes más desaventajados, por ejemplo mediante del establecimiento de alguna pauta en su favor. Y todo ello sin necesidad de abandonar totalmente la teoría del título válido ${ }^{23}$.

En resumen, la admisión de los actos mixtos permitiría enriquecer la teoría del título válido, refinando la aplicación del principio volenti non fit iniuria y permitiendo alcanzar con ello un equilibrio reflexivo por lo que a la relación entre justicia contractual y necesidad se refiere. Permitiría asimismo tender puentes entre la justicia conmutativa -que Nozick por lo demás trata brillantemente- y la justicia distributiva, sin que ello supusiera

\footnotetext{
$20 \mathrm{Y}$ tal vez la única solución que se puede ensayar dentro de un paradigma histórico -en el sentido de Nozickde la justicia.

21 La expresión "sin culpa de su parte" introduce, evidentemente, varias dificultades sobre las que no es posible extenderse aquí. La discusión sostenida entre los igualitaristas de la suerte acerca de la "suerte bruta" y la "suerte opcional" aborda, mutatis mutandi, algunas de esas dificultades. Al respecto, el lector puede consultar con provecho el segundo capítulo de Hirose (2015).

22 Admitir la posibilidad, ya no de declarar, sino tan solo de demandar la invalidez de todos los contratos celebrados con voluntad mixta introduciría, una incertidumbre intolerable en el tráfico jurídico (sin contar con el perjuicio que dicha posibilidad podría acarrear a las personas que resultarían previsiblemente excluidas de dicho tráfico al quedar a priori etiquetadas como potenciales demandantes de nulidad por falta de "voluntad perfecta"). Por eso, desde el punto de vista del derecho privado, el tratamiento que da Nozick al principio volenti non fit iniuria es el correcto. Sin embargo, aunque cierta, esta perspectiva es parcial (meramente "abstracta", diría un hegeliano). Debe, en consecuencia, ser complementada con la perspectiva global que conduce a la justicia distributiva.

23 Decimos "totalmente" pues la introducción de una pauta (por ejemplo "se debe dar X al más necesitado") supone abandonar parcialmente la teoría de la justicia de Nozick que es una teoría histórica y no pautada. El reconocimiento de la teoría de los actos mixtos debiera conducir a aceptar una teoría histórica y pautada. El alcance de la pauta, evidentemente, podrá ser objeto de ulteriores discusiones (por ejemplo, en lo que concierne a la determinación del mínimo aceptable a partir del cual se entiende que ya no hay necesidad o en la determinación del grupo de los "más necesitados").
} 
renunciar a los principios generales de la teoría del título válido ${ }^{24}$. Y todo ello sin necesidad de meterse en la espinosa cuestión del "precio justo".

\section{c) Voluntariedad, BUENA FE CONTRACTUAL E INTERCAMBIO IMPRODUCTIVO}

Pero ¿puede realmente Nozick evitar el problema del precio justo? ¿Permite su teoría determinar los términos justos de intercambio sin apelar en ningún momento a algún concepto de "precio justo"? Estos problemas nos devuelven finalmente a la tercera de las preguntas planteadas al principio: ¿es realmente no solo necesaria sino también suficiente la exigencia de voluntariedad para considerar un intercambio como "justo"?

En la tradición aristotélica se exige para la justicia de los intercambios no solo que estos se cierren de modo voluntario, sino que exista también equivalencia en el valor de los objetos intercambiados ${ }^{25}$. Pero ¿por qué exigir esa equivalencia? En términos generales, la justicia, dice Aristóteles, es una cierta igualdad, aunque una igualdad que se realiza de distintas maneras dependiendo de la situación de que se trate. En el caso de los intercambios se tratará de una igualdad aritmética: cada parte debe dar tanto como lo que recibe. De otro modo se rompería la igualdad. Esta exigencia de igualdad no obsta a que, por otra parte, la equivalencia en las prestaciones solo pueda establecerse de modo aproximado y no con exactitud matemática. El intento por esclarecer y sistematizar las condiciones de dicha equivalencia en el contrato de compraventa conduce, dentro de la tradición aristotélica, a la teoría del precio justo.

Aun cuando Nozick crea que una teoría general de la justicia conmutativa puede prescindir del problema del precio justo ${ }^{26}$, su exigencia, formulada en la primera parte de ASU, de que los intercambios sean mutuamente productivos le empuja, sostiene Rothbard $^{27}$, en dirección a una teoría tal ¿̨leva razón Rothbard?

Para explicar el problema que conduce a Nozick a postular la necesidad de productividad recíproca de los intercambios, detengámonos en la siguiente explicación del español Domingo Báñez:

"Ahora bien, el consentimiento mixto de voluntario e involuntario no elimina la razón formal de lo injusto [...] Por ejemplo, si uno, en un acto voluntario para salvar la vida, ofrece dinero a un ladrón que le amenaza de muerte, realmente sufre injusticia de parte del ladrón, receptor del dinero, dado que la oferta voluntaria de dinero no es pura, sino mixta de voluntario e involuntario" 28 .

\footnotetext{
24 Evidentemente un libertario estricto podría afirmar que la introducción de la categoría del acto mixto desdibuja el libertarismo y que, por lo mismo, no ofrece ninguna ventaja. Nozick, por su parte, podría además haber considerado que su teoría de la justicia pierde en lugar de ganar con la introducción de un tertium quid como el acto mixto, al menos en la medida en que con esa introducción ASU habría perdido parte de su tono provocativo. Además, después de todo, parte del éxito de esa obra estriba, seguramente, en la proeza de haber reducido en ella toda la justicia a la sola justicia conmutativa.

25 Aristóteles, E.N., V, 5, 1133a33-1133b1; para la demanda de equivalencia, Aquino, S.T. II-IIae, q. 77, a.1; para una exposición más elaborada de la teoría escolástica del precio justo, cf. Molina (2011) pp. 151-174.

26 Por ejemplo, Nozick (1988) p. 72, nota al pie.

27 Rothbard (1995) p. 334

28 BAÑEZ (2008) p. 161.
} 
El caso descrito en este pasaje ¿es injusto según la teoría de la justicia de Nozick? ¿Lo es según otras teorías libertarias? ¿Lo es para autores anarcocapitalistas que, mutatis mutandi, adhieren a la teoría del título válido? Puesto que ni Nozick ni otros autores representativos de la tradición libertaria y anarcocapitalista parecen contemplar el tertium quid del acto mixto de voluntario e involuntario, no pueden, como Báñez, declarar como injusto el "acuerdo" al que llegan el ladrón y su víctima en razón del consentimiento "imperfecto" de esta última. En su lugar pueden, empero, decir sencillamente que el intercambio es injusto porque el ladrón no tiene derecho a robar y a amenazar de muerte a su víctima (el robo y la amenaza de matarle atentan contra la propiedad que la víctima tiene sobre sí misma, etc.).

Aunque Nozick estaría de acuerdo, evidentemente, con esta última razón, podría aún añadir otra: el acuerdo ofrecido por el ladrón es nulo porque en él tiene lugar un "intercambio improductivo". Para que un intercambio resulte vinculante, dice Nozick, es necesario que sea productivo para ambas partes. El ejemplo de Báñez cae precisamente dentro de lo que Nozick denomina "intercambios no productivos" ${ }^{29}$. ¿Cuáles son estos intercambios? Aquellos en que -excluidos el error y el engaño- convergen los siguientes supuestos: 1) una de las partes no recibe beneficio alguno con su celebración (de modo que con ella su posición resulta empeorada y no mejorada) y 2) a través del intercambio, una de las partes simplemente compra "el alivio de algo que no lo amenazaría si no existiera la posibilidad de un intercambio para obtener alivio de él”30. La primera condición es, dice Nozick, necesaria pero no suficiente para que el intercambio sea improductivo; la segunda es condición suficiente de un intercambio improductivo ${ }^{31}$.

Ciertamente la explicación de Nozick del intercambio improductivo es difícil. A ello se debe añadir que dicha explicación forma parte del intrincado argumento que ofrece en la primera parte de ASU en favor del Estado mínimo. Con todo, los ejemplos de actividades no productivas que ofrece, como el chantaje y la protección gansteril, contribuyen a clarificar la explicación, y especialmente la segunda de las condiciones mencionadas, la condición suficiente, que es la que más dificultades presenta: para que un intercambio sea improductivo, dice Nozick, no basta solo con que uno de los contratantes vea empeorada su posición, es necesario además que el otro obtenga una ventaja usando para ello a su contraparte ${ }^{32}$. Y como cualquier lector atento de Kant sabe, aquí es importante añadir la cláusula "como mero medio" ¿por qué? Porque en todos los intercambios, incluso en los productivos, las partes se usan recíprocamente como medios para obtener un beneficio. La diferencia entre un intercambio productivo y uno improductivo es que en el primero las partes se usan como un medio mientras que en los segundos una usa a la otra como un "mero" medio ${ }^{33}$. Así, el médico usa al paciente como un medio para obtener

\footnotetext{
29 Nozick (1988) pp. 90 y ss.

30 Nozick (1988) p. 91.

31 Es importante no perder de vista que de concurrir solo la primera de las condiciones señaladas no hay propiamente un intercambio no productivo. Así, por ejemplo, cuando un enfermo acude a un curandero en lugar de un médico, no existe un intercambio improductivo aun cuando el curandero esté de mala fe (i.e., sepa positivamente que la magia es ineficaz para restablecer la salud).

32 Nozick (1988) p. 91.

33 Mack parece perder de vista esta distinción entre "usar" y "meramente usar" y por eso afirma, erróneamente, que la segunda de las condiciones para la improductividad que identifica Nozick es satisfecha "en todos los intercambios típicos de libre mercado" (MACK, 1982, p. 178).
} 
una ganancia pero no lo utiliza como un "mero" medio. Ese solo sería el caso si es que no tuviera realmente conocimientos de medicina o le diera un diagnóstico erróneo a sabiendas o le obligara a atenderse con él. A la inversa, el paciente usa al médico, pero no lo usa como un "mero" medio porque le retribuye -mediante un pago- por sus servicios. Solo lo haría si es que lo forzara a prestarle sus servicios o no le pagara luego por ellos. En el caso de la protección gansteril, en cambio, el gánster utiliza al comprador como "mero" medio, pues no hace otra cosa que vender la abstención de su propia agresión. El comprador aquí simplemente compra su propia integridad a alguien a quien él no ha agredido. Otro tanto ocurre con el chantaje o la extorsión. Por consiguiente, la segunda condición, la condición suficiente del intercambio improductivo, puede reformularse en los siguientes términos: un intercambio es improductivo cuando una de las partes procura una ventaja por medio de la mera instrumentalización de la otra.

¿Tiene sentido la idea de "intercambio improductivo" introducido por Nozick en su teoría de la justicia? Por medio de la noción de “intercambio improductivo" Nozick está en condiciones, de proscribir "acuerdos" como la protección gansteril y el chantaje que -pace Block y Rothbard ${ }^{34}$ - no son ni pueden ser tenidos como válidos sin avalar al que está de mala fe. Dicho de otro modo, gracias al requisito de productividad recíproca de los intercambios, Nozick está en condiciones de proscribir ciertas formas de instrumentalización no consentida. Dicha proscripción se ajusta a una exigencia elemental de justicia y permite dar cabida a uno de los principios generales del derecho privado: la buena fe contractual. Seguramente no resultaría exagerado decir que esto debiera ser más que suficiente para demostrar la necesidad y conveniencia de incluir el concepto de "intercambio improductivo" en la tradición libertaria y anarcocapitalista, dada a considerar el chantaje y la extorsión como formas legítimas de "intercambio".

\section{d) INTERCAMBIO IMPRODUCTIVO Y PRECIO JUSTO}

Nozick ofrece una prueba de la "improductividad" de "intercambios" como el chantaje y la protección gansteril. Al respecto dice que:

"[S]i fueran imposibles o coactivamente prohibidos de manera que todo el mundo supiera que no podrían ser realizados, una de las partes del intercambio potencial nunca estaría peor" ${ }^{35}$.

Esta prueba es semejante a la afirmación que sirve de punto de partida a la escolástica para el examen de la compraventa: el contrato de compraventa ha sido instituido en interés de ambos contratantes ${ }^{36}$. Como ella, pareciera conducir igualmente al concepto de precio justo. Sin embargo, además de desechar en algunos pasajes la relevancia de la teoría del precio justo, en una nota al pie Nozick afirma que:

"Opiniones anteriores han sostenido que tiene que haber cierto tipo de igualdad entre los bienes que las personas están dispuestas a intercambiar. Porque de otra manera,

\footnotetext{
34 “¿Qué es exactamente el chantaje? El chantaje es una oferta de intercambio. Es la oferta de intercambiar algo, normalmente silencio, por algún bien, normalmente dinero”. BLOCK (2012) p. 83.

35 Nozick (1988) p. 91.

36 Por ejemplo, Aquino, S.T. II-IIae, q. 77, a.1.
} 
se pensaba, una parte sería el perdedor. En respuesta, los economistas señalan que los intercambios mutuamente ventajosos requieren únicamente preferencias opuestas. Si una persona prefiere tener el bien del otro a tener el suyo y si, similarmente, la otra persona prefiere tener el bien del primero al suyo propio, entonces un intercambio puede beneficiar a ambos. Ninguno perderá, aun cuando no exista nada por lo que se pueda predicar que sus bienes sean iguales" 37 .

Rothbard parece creer que el requisito de productividad de los intercambios exige que las prestaciones de las partes sean equivalentes en algún sentido objetivo. Por eso, después de decir que el requisito de la productividad de los intercambios conduce al problema del precio justo, se siente en la necesidad de explicar, contra Nozick, que los teólogos medievales no pudieron en sus disquisiciones acerca de estos problemas, llegar a otra conclusión que el precio justo era el precio de mercado. Sin embargo, tanto esta crítica como la explicación subsiguiente parecen fuera de lugar. En el pasaje precedente Nozick cita con aprobación la idea dominante entre los economistas de que basta que las preferencias sean diferentes (pero complementarias, se entiende) para que un acuerdo sea mutuamente ventajoso. Eso equivale a decir, con vistas a la celebración de intercambios, que las cosas valen tanto como cada uno las estime. Esta postura, propia de quienes defienden una teoría subjetiva del valor, es consistente, por lo demás, con la teoría económica que, en palabras de Nozick, ofrece el modelo adecuado de comprensión de los fenómenos económicos ${ }^{38}$. De aquí se siguen varias cosas.

1) Si alguien se empeñara en rebuscar una teoría del valor en ASU para, a partir de ella, atribuirle alguna teoría del precio justo, como mucho podría concluir que Nozick adhiere a una teoría subjetiva del valor y que, en consecuencia, defiende que las cosas valen tanto como los individuos estén dispuestos a pagar por ellas. Poco más es lo que se podría decir de la (presunta) teoría de Nozick del precio justo. Pero esto no significaría otra cosa que, de tener una posición a este respecto, la de Nozick no habría sido muy diferente de aquella que (respecto del precio justo "natural") sostuvieron los autores medievales a que se refiere Rothbard.

2) Podría sostenerse que una teoría del precio justo como la descrita, disuelve en realidad el problema de la equivalencia de las prestaciones en el de la voluntad de contratar. Aquí ha desaparecido la "equivalencia" concebida como la comparación de dos objetos. Es la voluntad de los contratantes la que reduce, en virtud de su interés común, dos objetos a la igualdad, por diferentes que sean en otros sentidos. Así las cosas ¿no se torna superflua la teoría del precio justo, que entonces viene a decir que un intercambio es justo sencillamente porque las partes quieren celebrarlo? ${ }^{39}$ ¿Y no demuestra el pasaje reproducido arriba que Nozick es consciente de esta consecuencia?

3) Las dos condiciones que Nozick menciona para el intercambio improductivo pueden reducirse, en rigor, a una, la segunda de ellas. En virtud de lo dicho en el punto

\footnotetext{
37 Nozick (1988) p. 72, nota al pie.

38 Véase Nozick (1988) p. 186, nota al pie. Allí se refiere Nozick a la teoría de la competencia y empresarialidad de Kirzner.

39 ¿No le sucede esto acaso a los autores escolásticos al tratar del "precio natural” de algunos bienes (por ejemplo bienes suntuarios, bienes raros y valiosos, obras de arte y otros por el estilo)?
} 
anterior, basta con que esa condición se cumpla para que ya no haya "precio justo" ni, por consiguiente, intercambio productivo. La razón de eso es simple: la voluntad de una de las partes se haya bajo coacción. Esto nos conduce al punto de partida, el principio volenti non fit iniuria. El hecho de que Nozick diga que la segunda condición es suficiente para que un intercambio sea improductivo confirma la interpretación que aquí se ha ofrecido.

4) En razón de todo lo anterior, hubiese sido mejor formular la prueba de la improductividad de los intercambios diciendo simplemente que son "improductivos" los intercambios o acuerdos que no pueden ser universalmente queridos o aceptados. O que solo son productivos aquellos acuerdos en que puede unificarse la voluntad de los dos contratantes según una ley universal ${ }^{40}$. El chantaje es improductivo no porque no exista equivalencia entre las prestaciones (después de todo, podría ocurrir que la víctima de un chantaje estime aliviada que el precio del silencio del chantajista es bajo), sino porque -dicho en términos kantianos- no puede ser universalmente querido.

5) El requisito de productividad de los intercambios no es una doctrina ad hoc de Nozick para evitar ciertas posturas chocantes frecuentes en las teorías libertarias y anarcocapitalistas. Es, por el contrario, un requisito que refleja el principio volenti non fit iniuria y, en último término, el principio más general a que apela la teoría de la justicia de Nozick, el "principio kantiano subyacente". Permítasenos desarrollar la relación entre la exigencia de productividad y el principio kantiano subyacente con mayor detenimiento.

\section{e) INTERCAMBIO PRODUCTIVO Y “PRINCIPIO KANTIANO SUBYACENTE"}

Al comienzo de ASU, Nozick ha afirmado que las restricciones libertarias reflejan, en el ámbito político, el principio kantiano subyacente que ordena tratar a los individuos siempre como fines y nunca como meros medios. Esta afirmación encierra la ambiciosa tesis de que, en último término, el libertarismo es la única filosofía que prohíbe absolutamente la instrumentalización no consentida de unas personas por otras con vistas a la consecución de algún fin político ${ }^{41}$. Independientemente de la plausibilidad de esta tesis, sería de esperar que el tratamiento de los distintos derechos naturales libertarios y, en fin, el tratamiento de las diversas instituciones políticas y jurídicas libertarias reflejasen a cada paso -o intentaran hacerlo, al menos- el "principio kantiano subyacente" a que se refiere Nozick.

¿Es ese el caso de la justicia contractual? Y más concretamente ¿es ese el caso del requisito de productividad de los intercambios?

Antes responder estas preguntas, puede resultar ilustrativo considerar el modo en que Kant mismo trata el problema de la justicia contractual. Después de todo, no debiera resultar excesivamente temerario decir que Kant es un buen intérprete de lo que Nozick denomina el "principio kantiano subyacente".

\footnotetext{
40 Por ejemplo, Kant VI, 271, 32-34.

41 Es necesario recalcar que se trata de una instrumentalizacion "no consentida" pues Nozick, como el grueso de los autores libertarios, admite como licita la instrumentalización consentida (por ejemplo, venderse como esclavo). No debiera resultar necesario aclarar que esa admisión no implica que Nozick además crea que una instrumentalización como esa es edificante o laudable.
} 
Pues bien, por su parte Kant explica que la adquisición de un acto del arbitrio de otro (i.e., la adquisición de un derecho personal) solo puede tener lugar en conformidad con el principio universal del derecho ${ }^{42}$. Esto quiere decir, en buenas cuentas, que los acuerdos solo son lícitos y vinculantes únicamente cuando con ellos no se impide la coexistencia de las distintas libertades que se despliegan en conformidad con la ley universal. De aquí que la aplicación más obvia del "principio kantiano subyacente" a la justicia contractual sea el reconocimiento de la libertad para contratar y la proscripción de la contratación forzada: cada uno es libre de contratar con quien quiera mientras con ello no lesione la libertad de otros (que a su vez ejercen su libertad lícitamente); a la inversa, nadie puede forzar a nadie a contratar con él ni exigirle tampoco la realización de un hecho, a menos que este sea necesario para indemnizarle por la comisión de un delito del que ha sido víctima por su parte. Por consiguiente, solo en conformidad con ese principio que demanda la coexistencia de libertades según leyes universales pueden ser lícitos los contratos e intercambios en general ${ }^{43}$.

En la formulación kantiana es meridianamente claro que la extorsión, el chantaje, las presiones ilegítimas, la protección gansteril y otras conductas semejantes son contrarias a derecho. El orden jurídico -o, por ponerlo en términos libertarios, un orden de respeto general a los derechos individuales- sería imposible si el chantaje o la protección gansteril fueran practicados universalmente. Por ejemplo, yo puedo querer sin contradicción vivir en un estado de derecho (o en un orden de respeto general de los derechos individuales) y al mismo tiempo querer que los que han cometido delito sean condenados por ello; pero no puedo querer consistentemente vivir en un estado de derecho y simultáneamente querer ganar dinero omitiendo la denuncia de un delito a la justicia.

Aunque Nozick no diga expresamente que las condiciones de productividad de los intercambios derivan o reflejan el principio kantiano subyacente, es claro que con ellas persigue el mismo fin que Kant con su teoría de los contratos: proscribir los acuerdos que implican la mera instrumentalización de otro. El hecho de que el único beneficio que una de las partes obtenga de un intercambio es el alivio de un mal que no la habría amenazado de haber estado proscrita la posibilidad de realizar la oferta que le hizo su "contraparte", es precisamente un modo -algo enrevesado- de decir que no son conformes a derecho los contratos en que una de las partes procura una ganancia utilizando a la otra como un mero medio.

Así las cosas, el requisito de productividad de los intercambios refleja el principio kantiano subyacente y coincide en sus líneas generales, dicho sea de paso, con la teoría kantiana de los contratos. O coincide salvo por un pequeño gran detalle. Nozick entiende que el requisito de productividad de los intercambios exige únicamente que las partes no sea instrumentalizadas contra su voluntad. Kant entiende que el principio universal del derecho proscribe no solo la instrumentalización involuntaria sino también la consentida. Esta pequeña gran diferencia explica que Nozick admita el contrato de esclavitud y Kant no.

\footnotetext{
42 Kant, AA VI, 271. Kant formula el "principio universal del derecho" en AA VI, 230, 29-31.

43 Para un tratamiento más detallado de las condiciones bajo las cuales los contratos y los derechos reales son posibles y vinculantes para Kant, véase SCHWEMbER (2015).
} 
Seguramente tampoco resulte muy temerario afirmar que a este respecto Kant ha sido un mejor intérprete de su propio principio.

\section{CONCLUSIONES}

El principio kantiano subyacente ofrece un hilo conductor para establecer la continuidad entre los principales aspectos de la teoría de Nozick de los intercambios, la condición de productividad y la teoría del título válido. En este sentido, la lectura aquí ofrecida permite subrayar la unidad de la teoría de los contratos de Nozick y, en esa medida, de $A S U$ en su conjunto. Por lo mismo, esta interpretación permite desechar la tesis de Mack de que "los puntos de vista de Nozick con respecto a la productividad amenazan con subvertir la concepción fuertemente deóntica de los derechos con que comienza Anarquía, Estado y utopía" ${ }^{4}$. Si se verifica algún giro en la concepción de Nozick de los derechos, este no se explica por las condiciones de productividad exigidas a los intercambios. Dichas condiciones son concordantes con el principio volenti non fit iniuria y, en términos más generales, con el principio kantiano subyacente.

Sin embargo, y aunque subraya la continuidad y concordancia de la obra, esta lectura deja algunos flancos descubiertos. Si el requisito de productividad puede interpretarse como el mandato de no emplear como un mero medio a la contraparte de un acuerdo y si ello debe entenderse, en último término, no como el que las prestaciones sean objetivamente equivalentes sino como que lo sean solo subjetivamente (yo prefiero lo que tú tienes y viceversa), entonces tropezamos de nuevo con la dificultad apuntada al principio acerca de la estrechez de la noción de voluntariedad que maneja Nozick. Las "preferencias" podrán desplazar al "precio justo" como medida de la justicia de los intercambios solo si son escogidas de modo verdaderamente libre y esto quiere decir -como decían los escolásticos- que sean elegidas con voluntad perfecta. El hecho de que la víctima de un chantaje pague aliviada no quita que en parte no quiera hacerlo. Si es la voluntad la que reduce todos los bienes que se intercambian a un mínimo común denominador, entonces es oportuno e, incluso más, necesario contemplar los distintos grados de voluntariedad. De lo contrario, habrá que considerar el chantaje, la protección gansteril y otros "tratos" semejantes como justos. Así las cosas, la falta de un tertium quid entre lo voluntario y lo involuntario sigue haciendo sentir su necesidad en la teoría de la justicia de Nozick.

\section{BIBLIOGRAFÍA CITADA}

Aquino, Tomás de (1990): Suma de teología (Madrid: Biblioteca de Autores Cristianos). Aristóteles. (2002): Ética a Nicómaco (trads. M. Araujo y J. Marías, Madrid: Centro de Estudios Políticos y Constitucionales).

BÁÑEZ, Domingo. (2008): El derecho y la justicia: decisiones de iure et iustitia (trad. J. C. Cruz, Pamplona: EUNSA).

44 MaCK (1982) p. 186. Esta tesis Mack también la desarrolla en MACK (2011). 
BLock, Walter. (2012): Defendiendo lo indefendible (trad. D. G. Calle, Madrid: Unión Editorial - Innisfree editorial).

De Soto, Domingo. (1968): De iustitia et iure libri decem - De la justicia y el derecho en diez libros (Vol. II, trad. M. G. Ordóñez, Madrid: Instituto de Estudios Políticos).

Gaus, Gerald. (2011): "Explanation, justification, and emergent properties: an essay on Nozickian metatheory", en Bader, Ralf M. y Meadowcroft, John (edits.), The Cambridge Companion to Nozick's Anarchy, State, and Utopia (New York: Cambridge University Press) pp. 116-142.

Hunt, Lester. H. (2015): Anarchy, State, and Utopia. An Advanced Guide (Oxford: WileyBlackwell).

Hirose, Iwao. (2015): Egalitarianism. (Routledge: Abingdon - New York).

KANT, Immanuel. (1910-1917;1923-1972): Kants Gesammelte Schriften herausgegeben von der Königlich Preussischen Akademie der Wissenschaften (Vols. I-XXVIII, Berlin-Leipzig: Georg Reimer; Walter de Gruyter).

MACK, Eric. (1982): "Nozick on Unproductivity: The Unintended Consequences", en Paul J. (edit.), Reading Nozick. Essays on Anarchy, State and Utopia (Oxford: Basil Blackwell) pp. 169-190.

- (2011). Nozickian arguments for the more-than-minimal state. en BADER, Ralf M. y Meadowcroft, John (edits.), The Cambridge Companion to Nozick's Anarchy, State, and Utopia (New York: Cambridge University Press) pp. 89-115.

Molina, Luis de. (2011): La teoría del precio justo. (trad. F. G. Camacho, Valladolid: Maxtor).

Nozick, Robert. (1974): Anarchy, State, and Utopia (Oxford: Basic Books).

—_. (1988). Anarquía, Estado y utopía. (trad. R. Tamayo, México: Fondo de Cultura Económica).

Pufendorf, Samuel. (1998): Gesammelte Werke. De iure naturae et gentium, Vol. 4 (Berlin: Akademie Verlag).

Rothbard, Murray. N. (1995): La Ética de la libertad. (trad. M. V. Salas, Madrid: Unión editorial).

SCHWEMBER, Felipe. (2015): "Libertad, acción y argumentos trascendentales: la deducción de lo mío y lo tuyo externo en el derecho privado kantiano" en NAVARro, Juan Manuel, Orden Jiménez, Rafael V., y Rovira, Rogelio (eds.), Nuevas perspectivas sobre la filosofía de Kant (editorial Escolar y Mayo, Madrid) pp. 239247.

Vitoria, Francisco de. (2006): Contratos y Usura. (trad. M. I. Zorroza, Pamplona: EUNSA).

Wolff, Jonathan. (1991): Robert Nozick. Property, Justice and the Minimal State (Cambridge: Polity Press). 